\title{
Health Information Systems: a Survey of Frame- works for Developing Countries
}

\author{
A.B. Marcelo \\ University of the Philippines - National Telehealth Center, Manila, Philippines
}

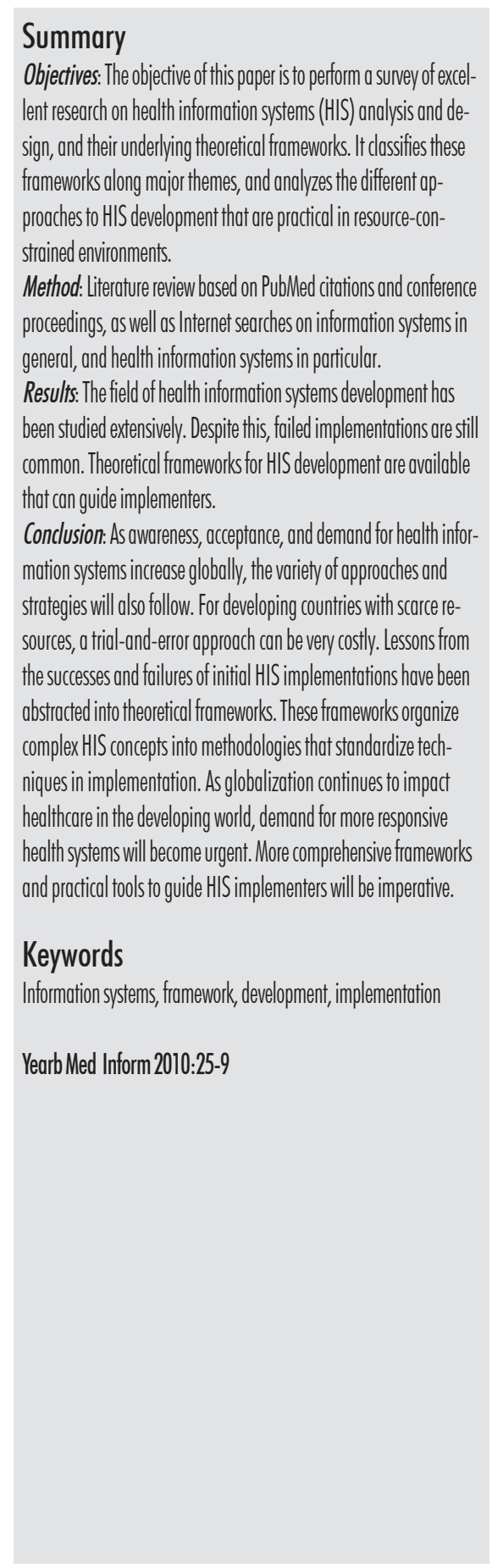

\section{Introduction}

In 2003, Littlejohns et al [1] described a failed health information systems project in Africa. In their post-implementation analysis, the authors listed several lessons from the project's demise ranging from deficiencies in infrastructure, gaps in project management, and challenges in organizational change. It received substantial attention because of the large amount of funding involved and drew criticism from different analysts for failing to elaborate on significant internal organizational issues [2-5]. At around the same time, Balka [6] reported a similar experience albeit in a more developed-country setting. In this case, the authors added external macrolevel issues (such as national policies that affected local labour relations) to be partly culpable with the project's struggles. A cursory review of literature reveals a number of studies detailing their own challenges and/or failures with health information systems development [7-13].

Although cost-effectiveness analysis from HIS implementations are at best mixed [14], the current sentiment is that HIS development is resource-intensive and requires time before a return on investment can be appreciated [15]. For developing countries, where financial and human resources are scarce, decisions to implement HIS must then be taken with great trepidation.

The objective of this survey is to understand the information systems development in general, and health information systems in particular, and identify contemporary theoretical frameworks that can guide developing countries toward their own effective implementations.

\section{Method}

In the first phase of the study, the authors obtained citations from MEDLINE on published studies on health information systems development and/or implementation, and theoretical frameworks. A second phase involved categorizing the result set under two categories: global (or system-wide) and component-based or application-specific (or sub-systems).

A total of one hundred seventy citations on "health information systems development" or "health information systems implementation" were found in the last ten years (Entrez date: 20002009). These were manually classified under either global or application-specific/component-based categories. Citations that fell under the global category were those that encompassed a wider scope involving several components of the larger health information system. Application-specific or component-based studies focused on smaller parts of an HIS like electronic prescription, patient safety, and/or ethics. These two categories (global and application-specific) were chosen to differentiate studies that could be generalized to larger HIS from those that dealt with more detailed aspects of a few HIS components.

Based on this criterion, twenty-two articles were classified as global while one hundred forty-eight concentrated on specific components of an HIS. Among the global articles, four articles that explicitly reported on frameworks were selected.

\section{Results}

Theoretical frameworks published by Aqil, Yusof, Killingsworth, and Heeks 
demonstrated unique approaches to health information systems development.

\section{Discussion}

The globalization of healthcare has begun to exert its effects on health information systems (HIS) in developed and developing countries [20] and subsequently, in the way health informatics professionals will be formed. As deployment of information technology become pervasive in the healthcare environment, the potential for entropy and systems disintegration will increase [12) unless structures and frameworks are put in place. Because HIS implementation is expensive, developing countries should be guided by well-defined strategies that can assure success with minimal costs. There is a need to review the current body of knowledge to extract best practice and lessons learned on HIS development and implementation to serve as benchmarks for emerging health systems.

To add complexity, technology changes rapidly. For example, mobile technology adoption is progressing quickly in the developing regions [21], and together with this, an anticipation for mobile health IT solutions in the fastest growing populations of the world. This demand and/or opportunity will require careful selection of strategies which may have worked in developed countries but may not adapt as well in developing ones.

The history of information systems (IS) in general and health information systems (HIS) in particular begins way back in the late eighties when initial research on IS began appearing in the literature.

In 1989, Hirschheim and Klein's categorized information systems development under four paradigms: functional, social relativitist, radical structuralist, and neohumanist. These paradigms served to explain the complex information system from various perspectives allowing space for the reader to navigate between any of the four.

In 1992, a landmark paper by Delone and McLean (D\&M) [22] defining in- formation system success triggered numerous studies attempting to validate and extend their model. This culminated in a meta-analysis [24] and in a subsequent update of the model by the authors themselves ten years hence [23]. Delone and McLean wanted to define the "dependent variable" for IS success and listed six interdependent elements as depicted in Figure 1. These were: system quality, information quality, use, user satisfaction, individual impact and organization impact. In 2003, they updated their success model into system quality, information quality, service quality, intention to use, use, user satisfaction, and net benefit (merging individual and organizational impact) (Figure 2). The modification was made in realization that the impact on individuals and organizations could not be categorically delineated. Interestingly, in the meta-analysis of the D\&M IS success model, there was no study that had tried to validate it for "health" information systems. It was much later when the D\&M began to be referenced in several HIS papers [25, 26].

Subsequently, other frameworks appeared in literature from Lind and Braa [27]. In 2000, the World Health Organization published an expansive reference for the design and implementation of health information systems (30). But up to this point, for frameworks, it was D\&M's IS success model that dominated the attention of many IS practitioners and theorists.

Yusof et al (17) suggested a qualitative framework based on HOT-fit $(\mathrm{Hu}-$ man, Organization and Technology fit). The authors emphasized the following critical adoption factors: "technology (ease of use, system usefulness, system flexibility, time efficiency, information accessibility and relevance); human (user training, user perception, user roles, user skills, clarity of system purpose, user involvement); organization (leadership and support, clinical process, user involvement, internal communication, inter-organizational system", including the fit between them. Using this framework, HIS implementers can be guided with system development and inform their decision making. This framework maps well with the D\&M IS success model.

Killingsworth et al [19] proposed a strategic information systems (SIS) formulation process that incorporated complexity theory, strategic/organizational analysis theory, and conventional management information systems development concepts. Four dimensions of the SIS are integrated in an implementation plan. Adopting this framework, hospitals will have the ability to recognize challenges to implementation and respond to external, inter-organizational, and intra-organizational influences. The authors provide a checklist that implementers can use for HIS development and implementation.

In 2000, Heeks published a series of papers [16] that described the importance of gap analysis in successful HIS implementation. His approach was unique, since up to that time, many analyses of health information systems

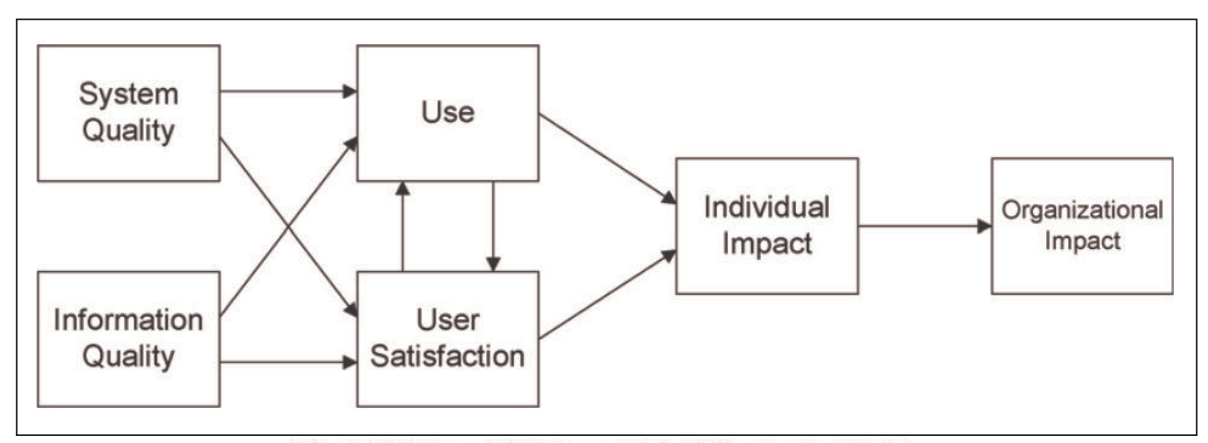

Fig. 1 Delone and McLean original IS success model.

Reprinted by permission. W. DeLone and E. Mclean. Information Systems Success: The Quest for the Dependent Variable. Information Systems Research 1992;3(1):60-95. Copyright 1992, The Institute of Management Sciences (now INFORMS), 901 Elkridge Landing Road, Suite 400, Linthicum, MD21090 USA. 
were divided between those who employed "factoral analysis" and those who defined information systems through complex IS concepts. Factoral analysis was an exegetical approach to rationalizing the body of knowledge through the dissection of conditions that affected or effected HIS. While important, such an analysis was limited because it did not explicitly ensure a set of actions to guide future HIS implementers. In the end, the lessons were learned but the options for action were diverse and unclear. On the other hand, there were hermeneutical perspectives from the information scientists but these did not employ language and constructs that were within easy reach of the HIS implementers. Heeks positioned himself in between these two approaches with his "designreality gap" model citing the importance of ascertaining the distance between vision and current situation and keeping it within manageable lengths. This pre-determined the level of effort that was needed to get from a starting point to a desired situation.

Heeks's "design-reality gap" model lists seven areas of concern (ITPOSMO which stands for information, technology, processes, objectives and values, staffing and skills, management, and other resources such as funding) and demonstrated the value of placing explicit attention on the gaps that exist between current reality and the proposed design for new systems. The larger the gap, the higher the chance of failure while too small gaps may not demonstrate observable change. On top of the ITPOSMO gaps, Heeks posited three other types of gaps that can occur: country context, hard-soft, and private-public gaps.

More recently, the Health Metrics Network [28] launched a campaign to assist countries strengthen their health information systems. HMN proposed an overarching framework that sets standards on HIS components and data sources with a clear goal towards harmonization.

The HMN Framework (Figure 3) was designed to help countries build stronger systems that can collect, man-

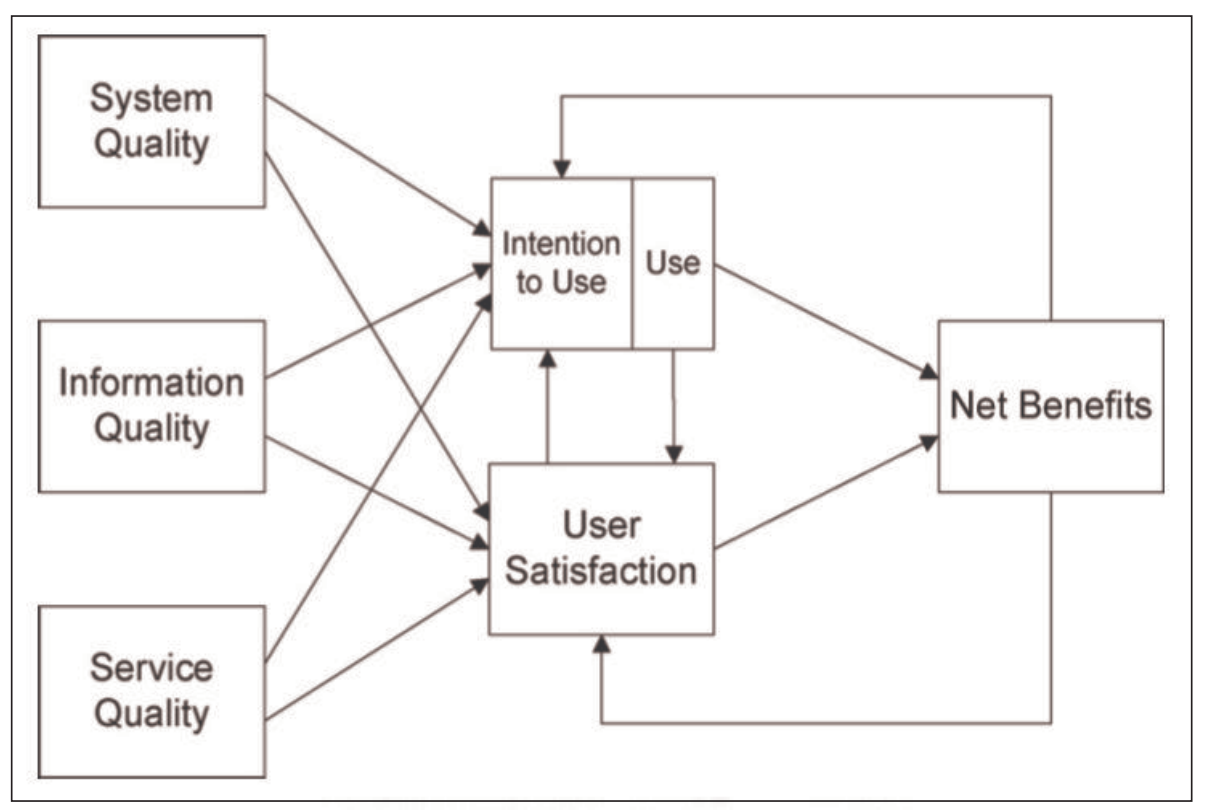

Fig. 2 Delone and McLean updated IS success model

Reprinted by permission. W. DeLone and E. Mclean. Information Systems Success: The Quest for the Dependent Variable. Information Systems Research 1992; 3(1):60-95. Copyright 1992, The Institute of Management Sciences (now INFORMS), 901 Elkridge Landing Road, Suite 400, Linthicum, MD 21090 USA.

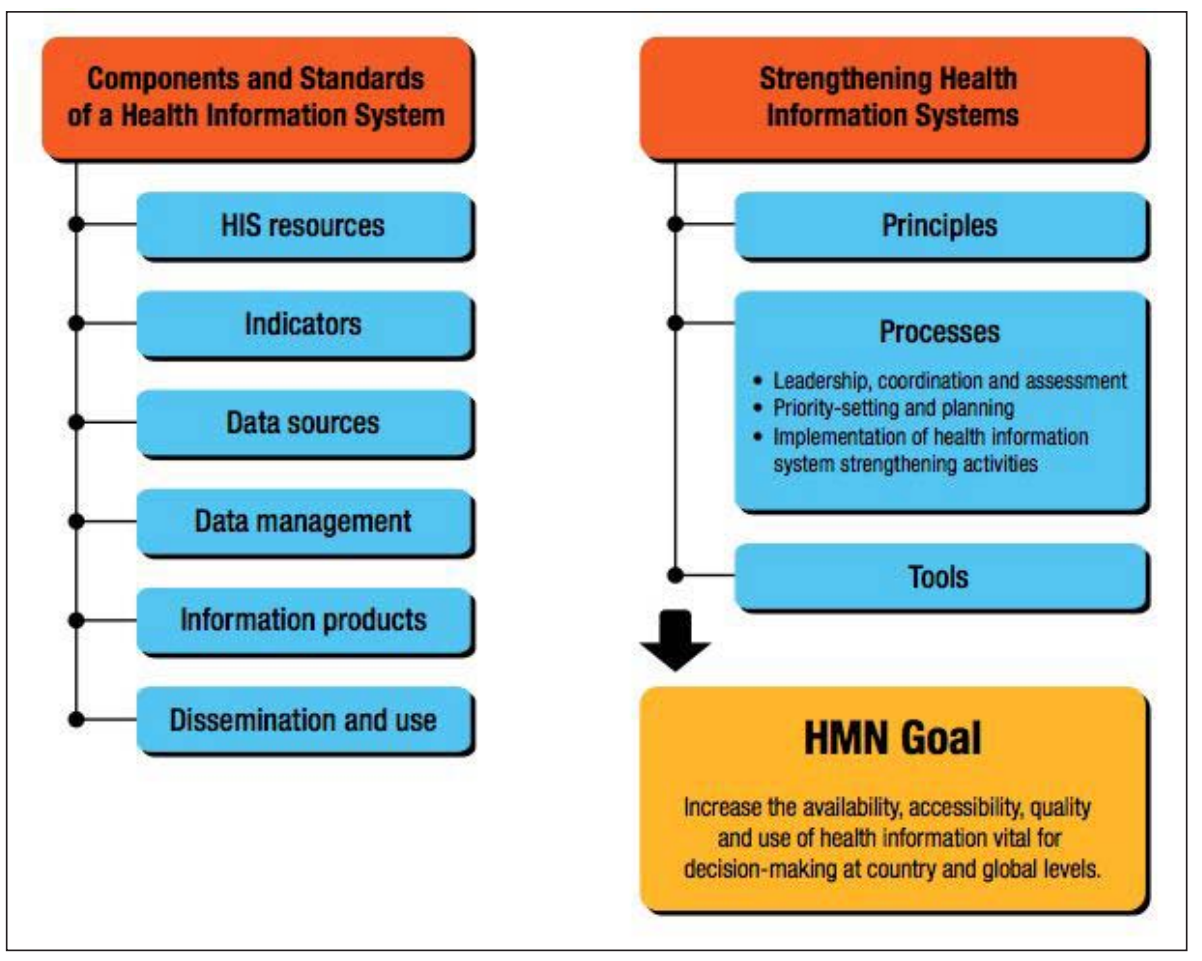

Fig. 3 The Health Metrics Network Framework

Reprinted by permission. World Health Organization. Framework and standards for countray health information systems / Health Metricc Network; 2008. p. 4. Copyright 2008 World Health Organization, Avenue Appia 20, CH-1211 Geneva 27, Switzerland. 
age, analyze and present health information, and allow it to improve health system responsiveness. The Framework lists the necessary components for an effective system and explains how the HIS can be evaluated. HMN builds on the foundations of principles, processes and practical tools to assist developing countries with their HIS design and implementation.

One framework that fits within the HMN, is the Performance of Routine Information Systems Management or PRISM Framework [17] which places special focus on information systems performance rather than specific program performance. PRISM stemmed from the MEASURE Evaluation [29] and offered a paradigm shift in HIS development. Whereas conventional methods measured success through indicators that resonated well with vertical surveillance systems, PRISM refocused attention to the maintenance of robust routine information systems and its internal organizational, technical, and behavioral determinants. The premise was that once routine information systems are performing well, improvement of the larger health system will follow.

The PRISM framework differs from most of the other papers in this survey in several respects. First, it promotes the idea of everyone's accountability and responsibility for the success (and failure) of HIS. By doing so, it eliminates the blaming process that often spell the early demise of an information system. Second, it introduces tools which require new skills to be learned as well as greater efforts in communication and advocacy. This is quite unique as it offers real-world templates to document health information systems performance as opposed to simply publishing a generic, abstract theoretical framework. In short, PRISM espouses both theory and praxis. Third, unlike Killingsworth's checklist, these tools are comprehensive and cover many aspects of HIS development. Though it may seem to be a formidable task to the uninitiated, PRISM is flexible enough to allow for selective implementation of the tools.

Table 1 Mapping Delone \& McLean with Heeks and PRISM frameworks

\begin{tabular}{|c|c|c|c|}
\hline D\&M IS success model & Heeks ITPOSMO & PRISM factor & PRISM determinant \\
\hline System quality & Technology Processes & Technical & $\begin{array}{l}\text { HIS design } \\
\text { Computer soffware } \\
\text { IT complexity }\end{array}$ \\
\hline \multirow[t]{2}{*}{ Information quality } & \multirow[t]{2}{*}{ Information } & Technical & Complexity of the reporting form, procedures \\
\hline & & RHIS processes & Data collection \\
\hline Service quality & $\begin{array}{l}\text { Staffing and skills } \\
\text { Management } \\
\text { Other (funding) }\end{array}$ & Organizational & $\begin{array}{l}\text { Governance } \\
\text { Planning } \\
\text { Availability of resources } \\
\text { Training } \\
\text { Supervision } \\
\text { Finances } \\
\text { Information distribution } \\
\text { Promotion of culture of information }\end{array}$ \\
\hline Intention to use/Use & Objectives and values & Behavioral & $\begin{array}{l}\text { Data demand } \\
\text { Data quality checking skill } \\
\text { Problem solving for HIS tasks } \\
\text { Competence in HIS tasks } \\
\text { Motivation }\end{array}$ \\
\hline User satisfaction & Staffing and skills & RHIS processes & $\begin{array}{l}\text { Data transformation } \\
\text { Data processing } \\
\text { Data analysis } \\
\text { Data display } \\
\text { Data quality checking } \\
\text { Feedback }\end{array}$ \\
\hline Net benefits & $\begin{array}{l}\text { Bridged design-reality } \\
\text { gaps }\end{array}$ & $\begin{array}{l}\text { Improved RHIS } \\
\text { performances }\end{array}$ & $\begin{array}{l}\text { Data quality } \\
\text { Information use } \\
\text { Improved health system performance } \\
\text { Improved health status }\end{array}$ \\
\hline
\end{tabular}

Though differently named, the frameworks in this survey did show recurring themes. A mapping of the updated D\&M information systems success model, Heeks, and the PRISM framework is shown in Table 1.

\section{Conclusions}

With the expected surge in demand for health IT, theoretical frameworks for analysis will be needed to standardize comprehension of the domain and enhance communications among practitioners. These frameworks must be simple yet expansive and must serve to codify the understanding of complex health systems to make HIS design more interoperable in an increasingly globalized environment. Making these theories suitable to both developed and developing world settings will be a continuing challenge.

As the cost of ownership of health IT hardware and software reach the capacities of developing countries, there will be increased attempts to implement HIS in these areas. Since HIS implementation is resource-intensive, it serves the developing world well if they are guided by the theoretical frameworks extracted from the successes and failures of past implementations.

Theoretical frameworks for health information systems bring tremendous value especially for emerging communities where knowledge of the domain may be lacking or incomplete. The 
HMN and PRISM frameworks attempt to explain the complexity of evaluating health information systems, and propose a way of looking at HIS development through culturally acceptable methodologies, by encouraging organizational accountability, and by offering actual standards and tools that can be used in many contexts.

\section{References}

1. Littlejohns P, Wyatt JC, Garvican L. Evaluating computerised health information systems: hard lessons still to be learnt. BMJ $2003 \mathrm{Apr}$ 19;326(7394):860-3

2. Longano BA. Evaluating computerised health information systems: Article contains inaccuracies. BMJ 2003 Jul 17;327(7407):163.

3. Ladner J, Digbeu H, Marquis F, Bi BG. Evaluating computerised health information systems: Health professionals should be closely involved in implementation. BMJ 2003;327:163-a.

4. Winkelman WJ. Evaluating computerised health information systems: Opportunities were missed. BMJ 2003 Jul 17;327(7407):162-b-163.

5. Evans MG. Evaluating computerised health information systems: We are still getting information technology wrong. BMJ. 2003 Jul 17;327(7407):163-b-164.

6. Balka E. Getting the big picture: the macro-politics of information system development (and failure) in a Canadian hospital. Methods Inf Med 2003;42(4):324-30.

7. Nykänen P, Karimaa E. Success and failure factors in the regional health information system design process - results from a constructive evaluation study. Methods Inf Med 2006;45(1):85-9.

8. Kleinke JD. Dot-gov: market failure and the creation of a national health information technology system. Health Aff (Millwood) 2005 Oct;24(5):1246-62.

9. Scott JT, Rundall TG, Vogt TM, Hsu J. Kaiser Permanente's experience of implementing an electronic medical record: a qualitative study. BMJ 2005 Dec 3;331(7528):1313-6.

10. Mate KS, Bennett B, Mphatswe W, Barker P, Rollins N. Challenges for routine health system data management in a large public programme to prevent mother-to-child HIV transmission in South Africa. PLoS ONE 2009;4(5):e5483.

11. Saleem JJ, Russ AL, Sanderson P, Johnson TR, Zhang J, Sittig DF. Current challenges and opportunities for better integration of human factors research with development of clinical information systems. Yearb Med Inform 2009;:48-58.

12. Wetter T. To decay is system: the challenges of keeping a health information system alive. Int $\mathrm{J}$ Med Inform 2007 Jun;76 Suppl 1:S252-60.

13. Ammenwerth E, Schnell-Inderst P, Siebert U. Vision and challenges of Evidence-Based Health Informatics: a case study of a CPOE meta-analysis. Int J Med Inform $2010 \mathrm{Apr} ; 79(4)$ :e83-8.

14. Chaudhry B, Wang J, Wu S, Maglione M, Mojica W, Roth E, et al. Systematic review: impact of health information technology on quality, efficiency, and costs of medical care. Ann Intern Med 2006 May 16;144(10):742-52.

15. Shekelle PG, Morton SC, Keeler EB. Costs and benefits of health information technology. Evid Rep Technol Assess (Full Rep) 2006 Apr;(132):1-71.

16. Heeks R. Health information systems: failure, success and improvisation. Int J Med Inform 2006 Feb;75(2):125-37.

17. Aqil A, Lippeveld T, Hozumi D. PRISM framework: a paradigm shift for designing, strengthening and evaluating routine health information systems. Health Policy Plan 2009 May;24(3):217-28.

18. Yus of MM, Stergioulas L, Zugic J. Health information systems adoption: findings from a systematic review. Stud Health Technol Inform 2007:129(Pt 1):262-6.

19. Killingsworth B, Newkirk HE, Seeman E. An integrative health information systems approach for facilitating strategic planning in hospitals. Health Care Manage Rev 2006 Jun;31(2):119-29.

20. Simba DO, Mwangu M. Application of ICT in strengthening health information systems in developing countries in the wake of globalisation. Afr Health Sci 2004 Dec;4(3):194-8.

21. Worldwide Mobile Market Forecasts 2006-2011 MobileIN.com [Internet]. [cited $2010 \mathrm{Apr}$
4];Available from: http://www.mobilein.com/ reports/PR/WW_Mobile_Forecasts_2006-2011.php

22. DeLone WH, McLean ER. Information Systems Success: The Quest for the Dependent Variable. Information Systems Research 1992 Mar 1;3(1):60-95.

23. Petter S, McLean ER. A meta-analytic assessment of the DeLone and McLean IS success model: An examination of IS success at the individual level. Information \& Management 2009 Apr;46(3):159-66.

24. Delone WH, McLean ER. The DeLone and McLean model of information systems success: A ten-year update. Journal of Management Information Systems 2003;19(4):9-30.

25. Lau F, Hagens S, Muttitt S. A proposed benefits evaluation framework for health information systems in Canada. Healthc Q 2007;10(1):112-6, 118.

26. Lau F. Extending the infoway benefits evaluation framework for health information systems. Stud Health Technol Inform 2009;143:406-13.

27. Lind A, Lind B. The practice of information system development and use: a dialectical approach. Systems Research and Behavioral Science 2005;22(5):453-64

28. WHO | Welcome to HMN [Internet]. [cited 2010 Apr 4];Available from: http://www.who.int/ healthmetrics/en/

29. PRISM: Performance of Routine Information System Management Framework - UNC Carolina Population Center [Internet]. [cited $2010 \mathrm{Apr}$ 5];Available from: http://www.cpc.unc.edu/measure tools/monitoring-evaluation-systems/prism

30. Design and Implementation of Health Information Systems - WHO - OMS - [Internet]. [cited 2010. Apr 12];Available from: http://apps.who.int/ bookorders/anglais/detart1.jsp?sesslan $=1 \&$ codlan $=1 \& \operatorname{cod} \operatorname{col}=15 \& \operatorname{cod} \operatorname{cch}=479$

Correspondence to:

Alvin B. Marcelo, MD

University of the Philippines Manila - National Telehealth Center

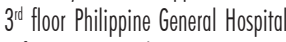

Taft Avenue, Manila

PHILIPPINES 1000

Tel: +6324262315

Fax: + 632522923

E-mail: alvin.marcelo@iosnasean.net 